\title{
The Implementation of Problem-Based Learning (PBL) in a Year 9 Mathematics Classroom: A Study in Brunei Darussalam
}

\author{
Haji Mohammad Redzuan Haji Botty \\ Ministry of Education \\ Brunei Darussalam
}

Masitah Shahrill

Sultan Hassanal Bolkiah Institute of Education, Universiti Brunei Darussalam

Brunei Darussalam

Jainatul Halida Jaidin

Sultan Hassanal Bolkiah Institute of Education, Universiti Brunei Darussalam Brunei Darussalam

\section{Hui-Chuan Li (Corresponding author)}

Sultan Hassanal Bolkiah Institute of Education, Universiti Brunei Darussalam

Brunei Darussalam

E-mail: huichuan.li@ubd.edu.bn

Maureen Siew Fang Chong

Brunei Darussalam Teacher Academy, Ministry of Education

Brunei Darussalam

Received: May 27, 2016

doi:10.5296/ire.v4i2.9466
Accepted: June 27, 2016 Published: August 24, 2016

URL: http://dx.doi.org/10.5296/ire.v4i2.9466 


\section{Abstract}

Problem-Based Learning (PBL) is a constructivist, student-centered instructional strategy in which students work collaboratively to solve problems and reflect on their learning experiences to advance or gain new knowledge. PBL was originally developed in medical school programs at the McMaster University in Canada in the 1960s. Since then, much research has highlighted the benefits of PBL for developing students' mathematical knowledge in more flexible and novel ways than traditional teacher-centered teaching approaches. However, there has been a lack of studies examining how PBL can be applied to mathematics teaching and learning, since studies that have investigated the implementation of PBL outside a medical context are sparse in Brunei Darussalam. Therefore, in this study, we attempted to fill this research gap by exploring the implementation processi of PBL in a Year 9 mathematics classroom and its possible impact on students' learning in mathematics in the context of Brunei Darussalam. The participants of the study consisted of 17 Year 9 students (ages 14-15) from a secondary school in Brunei Darussalam The findings from our study showed that the implementation of PBL helped motivate the students to collaboratively work as a group and learn from their peers and therefore, gradually reduced their dependence on the teacher during the course of the intervention. The results from the studlents' performances on the pre-test and the post-test also provided evidence to show that the implementation of PBL could have a positive impact on the students' learning in mathematics. Directions for future mathematical PBL implementation are also discussed and offered.

Keywords: problem-based learning (PBL), questioning techniques, facts list, mathematics, secondary school

\section{Introduction}

In Brunei Darussalam, mathematics teaching and learning tend to be dominant by teachers' instructions with very little opportunity for students to play an active role in their learning (Botty \& Shahrill, 2014, 2015). Such traditional teacher-centered and direct instruction pedagogical methods often undermine students' skills and responsibilities to become independent learners (Pham, 2011). The Ministry of Education in Brunei Darussalam recognized this pitfall and considered a need to change teaching and learning approaches. Consequently, a new system of education known as Sistem Pendidikan Negara Abad Ke-21 (SPN21) has been introduced and implemented in Brunei Darussalam from 2008 to present (Ministry of Education, 2013). SPN21 emphasizes students' development of the $21^{\text {st }}$ century skills in schools. These skills include knowledge construction, problem solving, collaboration, self-regulation, communication, and the use of ICT. Over the past decade, education communities, researchers and mathematics teachers in Brunei Darussalam are bombarded with demands to find feasible and effective ways to teach mathematic, in order to achieve the goals of SPN 21. An example of these strategies includes a student-centred approach to learning called Problem-Based Learning, or PBL in short.

PBL is a constructivist, student-centered instructional strategy in which students work collaboratively to solve problems and reflect on their learning experiencesi to advance or gain new knowledge (Adnan \& Shahrill, 2015; Burris \& Garton, 2007; Caesar et al., 2016; Han et 
al., 2016; Khalid \& Rahman, 2014; Lim et al., 2016; Othman et al., 2015). PBL was originally developed in medical school programs at the McMaster University in Canada in the 1960s (Barrows \& Tamblyn, 1980). Now, there have been various adaptations of PBL across many levels and subject areas (Hung, 2011; Chin \& Chia, 2005). Generally, the content of a lesson in PBL is organized "as a problem or a series of problems, rather than in a textbook form" (Li, 2012, p. 89). The PBL problems aim to provide opportunities for students to construct and develop their knowledge during the process of solving the problems with group members (Preechaporn \& Tat, 2012). PBL emphasizes the importance of collaboration on students' learning (Ebert \& Culyer, 2011). As Vygotsky (1978) and Moore (2012) noted, learning comes from social interactions and activities where knowledge transfers from one individual to another through verbal communication and demonstration.

Consequently, in PBL, students are expected to engage in the problem solving activities with their group members to attain the learning objectives (Wang \& Posey, 2011). Research also shows that the implementation of PBL can help increase students' motivation to be actively involved in the learning process (Gillies \& Boyle, 2010). Small-group discussions become the focus of the learning situations in PBL and the teacher becomes the facilitator of small-group discussions (Lambros, 2002). In other words, PBL teachers are not in classrooms to deliver contents to the whole class and ensure classroom control. Rather, they are expected to guide group discussions when students work on the given problem during the lesson (Ronis, 2008). It is essential that teachers use open-ended questioning techniques to help students demonstrate clarity of expression and effective exposition of points (Salam \& Shahrill, 2014; Shahrill, 2009, 2013a, 2013b; Shahrill \& Clarke, 2014; Shahrill \& Mundia, 2014).

Much research has highlighted the benefits of PBL for developing students' mathematical knowledge in more flexible and novel ways than traditional teacher-centered teaching approaches (Li, 2011; Li \& Stylianides, 2016; Wirkala \& Kuhn, 2011). However, there has been a lack of studies examining how PBL can be applied to mathematics teaching and learning (Botty \& Shahrill, 2015), since studies that have investigated the implementation of PBL outside a medical context are sparse in Brunei Darussalam. Consequently, more research needs to be conducted in order to understand how the implementation of PBL in mathematics classrooms can be successfully adapted by teachers in their classrooms, especially in Brunei Darussalam where both teachers and students are relatively new to PBL. A desire to enhance Bruneian students' proficiency with mathematics has driven us to conduct this case study, which involved the design and implementation of a PBL intervention in a Year 9 mathematics classroom in Brunei Darussalam.

The nature of PBL varies depending on three factors, namely: the education level, students' capabilities and subjects. The various PBL models have made PBL a flexible and robust pedagogical approach for affording different and unique instructional needs in specific contexts (Hung, 2011). In considering the unfamiliarity of the participating teacher with PBL, the simple form of Lee and Bae's (2007) six stages among variations of PBL models in educational settings was adapted for this study. These six stages are: (1) introduction, (2) identifying a problem statement, (3) searching for information, (4) constructing and 
supporting evidence for a proposed solution, (5) presentation, and (6) wrapping up the solution.

We were also aware that the participating students were also new to PBL and lacked experiences in working as a group when solving mathematical problems. The ways in which learning is experienced by students in Brunei Darussalam can generally be categorised into three main conceptions, namely: (1) learning as acquiring information, (2) learning as remembering, and (3) learning as doing hands-on activities (Jaidin, 2009; Rashid \& Jaidin, 2014). These conceptions of learning suggest that classroom practices in government schools in Brunei Darussalam are mainly teacher-centred and didactic. Consequently, in order for the teacher to guide small-group discussions, each group was given a "PBL Facts List" that asked them to identify: (1) "What do we know?", (2) "What do we need to know?", and (3) "How do we get the information?". This "PBL Facts List" was adapted from Lambros (2002).

Before the intervention, the first author provided a one-hour workshop with the participating teacher, which aimed to help her understand how to use the Lee and Bae's (2007) six stages for the implementation of PBL and how to use the "PBL Facts List" to guide students' discussions. It is important to note here that a change in the teacher's pedagogies from the teacher-centered teaching methods to PBL may not be easy to happen in teachers' practices (Li \& Stylianides, 2016; Reeve, 2006; Watkins, Carnell, \& Lodge, 2007). As Bridges and colleagues (2012) noted, "of critical importance is the need to contribute further interactional data and analysis on PBL-in-action to support theory building" (p. 99). Therefore, in this study, we attempted to fill this research gap by exploring the implementation process of PBL in a Year 9 mathematics classroom and its possible impact on students' learning in mathematics in the context of Brunei Darussalam. Specifically, we aimed to address the following two research questions:

1. How does the teacher interpret the implementation of PBL in a Year 9 mathematics classroom in Brunei Darussalam?

2. To what extent does the implementation of PBL have an impact on the students' performance on mathematics?

\section{Method}

\subsection{Participants}

Miss Diana's (a pseudonym) class of 17 Year 9 students (ages 14-15) from a secondary school in Brunei Darussalam was invited to take part in this PBL intervention. The school principal, the participating teacher, and the participating students all grant their informed consent to participate this study. The intervention was implemented by Miss Diana. At the time of the study, she had eight-year experience of teaching mathematics at secondary school. This was her first time to use our PBL model for implementing a PBL intervention in her classroom. However, it should be noted that she was not completely new to PBL as she had attended some in-country workshops relating to PBL before she joined our study. All the participating students were new to PBL and had no prior experience in learning mathematics through group work. 
It is also worth mentioning here that in Brunei Darussalam, when students enter their upper secondary schools, they are streamed into different programs, according, to their results on Students Progress Assessment (SPA) in Year 8. The participating students in this study were enrolled in the General Secondary Education Program which focuses more on students' academic performances than the other upper-secondary programs (Botty \& Shahrill, 2015). For example, all the students in this program are required to attend the Brunei-Cambridge General Certificate of Education (BCGCE) 'O' Level examination in Year 11.

In this study, we focused on the Year 9 students in the General Secondary Education Program for two main reasons. Firstly, we sought to examine the possible effect of PBL on students' performances on mathematics, in order to find a feasible teaching method for promoting upper secondary students' academic performances in the area of mathematics. Secondly, since Year 9 is the first year of the students' upper secondary education, this appeared to be the proper time for introducing a different learning method to students who just start their upper secondary years.

\subsection{The PBL Intervention}

It is important to note that it was difficult to find lesson time for this intervention, due to the busy teaching schedules in school. Therefore, Miss Diana had to find time to implement the PBL intervention from the students' regular mathematics lessons. She finally managed and arranged six lessons for implementing the PBL intervention (each lesson lasted 50-55 minutes). The intervention focused on the topic "Time \& Currency Exchange" in the Year 9 mathematics syllabus. The reason for choosing this topic was mainly because the teacher considered "Time \& Currency Exchange" as largely associated with real-life situations and as such served as a good start, when introducing the Year 9 students to PBL.

Miss Diana agreed to use the Lee and Bae's (2007) six stages for implementing this PBL intervention. She randomly divided her class into six groups. Each group consisted of two or three students. A piece of paper called as the "PBL Facts List" was also given to each group (hereafter referring to as "Facts List"). As mentioned earlier, this "Facts List" aimed to help groups organize their problem-solving procedures. Miss Diana also frequently checked groups' "Facts List" during the PBL lessons, with a view to monitoring groups' progress and guiding students to correct their mistakes. Furthermore, in order to allow opportunities for students to search information that they may need to solve the given PBL problem, each group was given a laptop with the availability of Internet access. They were also allowed to use the laptops to prepare PowerPoint slides for presenting their solutions to the whole class during the course of the intervention.

\subsection{Data Collection Methods}

This study employed a convergent mixed method approach in which both quantitative and qualitative data were collected and analysed in order to address our research questions (Creswell, 2014). The qualitative data collected in the study included: (i) video recordings of the classroom observations, (ii) the semi-structured teacher interviews, (iii) the teacher's reflective notes, (iv) the "Facts List" notes, and (v) the focus group student interview. The 
quantitative data comprised the students' scores on the pre-test and the post-test. The triangulation of the data from difference resources also helped to enhance the reliability of this study (Stake, 1995; Creswell, 2014). Each data collection method in this study will be briefly described below.

Each PBL lesson was video-recorded with permission, which also allowed all of us to observe this intervention. Miss Diana was also invited to watch the video-recordings after the lesson in order for her to review and reflect on how she implemented the lesson. When the intervention was completed, the semi-structured interview with the teacher (that lasted approximately 30 minutes) was conducted. The rationale for choosing the use of the semi-structured interview was mainly because we had a specific focus on the teacher's perceptions during the intervention (Burns, 1997). Furthermore, the face-to-face interview enabled the researchers to yield detailed descriptions of Miss Diana's perceptions of the intervention process.

After the completion of the intervention, three students were also selected for the focus group interview (approximately 30 minutes). As suggested by Punch (2005), the focus group interview works with several people simultaneously, which can help gather information from group interaction that may not be able to obtain from individual interviews. Miss Diana recommended the three selected students to be interviewed because of their good performances during the "Presentation" stage in the intervention.

A pre-test and a post-test were also given to all the students before and after the intervention, respectively. The pre-test and the post-test comprised of five similar questions, which were adapted from the syllabus of GCE ' $\mathrm{O}$ ' Level past-year questions in Brunei Darussalam. Two other mathematics educators were also invited to review the test questions in order to make sure that the wording and difficulty of the questions were appropriate to the participating students. Also, as Rudner and Schafer (2002) noted, questions of the same concept with just the numbers altered could be considered to be of equivalent difficulty. The duration of each test was twenty-five minutes.

\subsection{Data Analysis}

The student and teacher interviews and the video-recordings of the classroom observations were all transcribed for data analysis. The data from the teacher's reflective notes and the groups' "Facts List" notes were also analyzed to further understand how things were proceeding during the intervention. The pre-test and post-test were scored and compared in order to examine the differences in test scores between the pre-test and post-test. In addition, since measurements were administered to the same group twice (repeated measures) in this research study, a paired samples t-test was performed to examine whether there was a significant increase in students' performance on the test results (Leech, Barrett \& Morgan, 2012). SPSS version 21 was used to perform the statistical analyses. The significance level was set at 0.05 . 


\section{Results}

\subsection{The Teacher's Interpretation of This PBL Intervention}

According to the data derived from the classroom observations, the teacher interviews and the teacher's reflective notes, it provided an understanding of how the teacher interpreted PBL in her Year 9 mathematics classroom when teaching the topic "Time \& Currency Exchange". It was found that the teacher was able to follow and implement the Lee and Bae's (2007) six stages for the implementation of PBL.

In the "Introduction" stage, the teacher introduced the students to the given problem. Her efforts also included using several questioning techniques to help students understand the problem. For example, it was observed that when the students came to her for asking the meaning of the given problem, she did not directly provide an explanation. Instead, she asked the students several questions and encouraged them to look for answers through the use of Internet and discussion with their group members. In doing so, the students were also helped to go into the "Identifying a problem statement" stage. In this stage, with the facilitation from the teacher, groups gradually became able to identify: (1) "What do we know?" and (2) "What do we need to know?" and wrote down notes on the "Facts List".

In the next stage, the "Searching information" stage, Miss Diana paid close attention to monitoring the groups' progress by constantly checking the groups' "Facts List" notes relating to the question: "How do we get the information?". This "Searching information" stage not only took place during the lessons at school, but also was an ongoing activity for the students before they reached the stage of "Constructing and supporting evidence for a proposed solution". For example, one interviewed student mentioned that she asked her parents and her sister about how to calculate currency exchange, which suggested that the students made continuous commitments to solve the given problem, even after school time.

After groups gathered the necessary information to construct a solution for the given problem, they were asked to present their solutions to the whole class during the "Presentation" stage. It was observed that groups were able to present reasonable solutions for the problem. However, five out of six groups simply relied on the Internet for converting the currency from Brunei dollars to British pounds. These groups were not sure about how to convert the currency exchange when they were asked by Miss Diana. Only one group explained how they converted from Brunei dollars to British pounds during the "Presentation" stage. For example, they presented: "BND 88.5 as of GBP 70.8". However, the value "GBP 70.8" was actually in the exchange rate of US dollars. In the "Wrapping up stage”, Miss Diana gave feedback to the groups' presentations and concluded the learning objectives of the PBL lessons.

Overall, it was observed that Miss Diana showed commitments to facilitate small-group discussions. She approached each group several times during the intervention and asked questions to promote further discussion among group members. She also frequently emphasised on the importance of doing fair shares among the group members. The feedback from the interviewed students was also positive. All the interviewed students agreed that after 
the intervention, not only did they improve their understanding of how to convert time and currency exchange in difference places, they also developed teamwork skills. The teamwork skills were referred to as "extra knowledge" by one of the interviewed students.

\subsection{Students' Performances on the Test Results}

Table 1 shows the statistical results of the pre-test and post-test and the results of a paired sample t-test between the pre-test and post-test. As shown in Table 1, there was a mean increase (27.41) between the pre-test and post-test, with the latter had a higher mean score. It also shows that there was a statistically significant difference between the two tests, suggesting that the difference in the mean scores between the two tests was not simply due to chance (Pallant, 2010).

Table 1. The mean scores and the paired sample t-test results for the pre-test and the post-test

\begin{tabular}{lcccccc}
\hline & Mean & $\begin{array}{c}\text { Mean } \\
\text { difference }\end{array}$ & SD & $\begin{array}{c}\text { SD } \\
\text { difference }\end{array}$ & t-scores & Sig. $(p)$ \\
\hline Post-test & 67.65 & 27.41 & 17.09 & 11.16 & 4.33 & $0.01^{*}$ \\
Pre-test & 40.24 & & 28.25 & & & \\
\hline
\end{tabular}

It is important to note here that among the five questions in the pre-test and the post-test, the questions 1 and 4 were related to the students' ability to solve the problems embedded in the real-life situations, the questions 2 and 3 were concerned about the students' mathematical development that was stated in the learning objectives of the Year 9 mathematics syllabus in Brunei Darussalam, and the question 5 was to examine the students' prior knowledge in the area of "Time and Currency Exchange", which had been introduced to them in their previous school year - Year 8. Consequently, in this study, we referred these five questions to three areas: real-life knowledge, syllabus-required knowledge, and prior knowledge. The correct percentages of the students' responses relating to these three areas in the pre-test and the post-test were compared and presented in Table 2.

Table 2. The students' correct percentages of the questions in the pre-test and post-test

\begin{tabular}{ccrr}
\hline Areas & Questions & $\begin{array}{r}\text { Correct Percentage (\%) } \\
\text { Pre-test }\end{array}$ & $\begin{array}{r}\text { Correct Percentage (\%) } \\
\text { Post-test }\end{array}$ \\
\hline $\begin{array}{c}\text { Real-life } \\
\text { Knowledge }\end{array}$ & Questions 1 and 4 & 25 & 100 \\
\hline $\begin{array}{c}\text { Syllabus-required } \\
\text { Knowledge }\end{array}$ & Questions 2 and 3 & 38.9 & 52.9 \\
\hline Prior Knowledge & Question 5 & 77.8 & 44.4 \\
\hline
\end{tabular}


As shown in Table $2,100 \%$ of the students were able to correctly response to the questions 1 and 4 in the post-test, with an increase of $75 \%$ when compared with that of the results in the pre-test. This shows that there was improvement in students' real-life knowledge relating to the topic of "Time and Currency Exchange" after the completion of the intervention. There was also an increase of $14 \%$ in the correct percentages of the questions 2 and 3 between the pre-test and the post-test, suggesting that this PBL intervention may have a positive impact on the students' development of the syllabus-required knowledge. However, we were surprised to see that there was a decrease of $33.4 \%$ in the students' responses to the question 5. We further looked at each of the students' responses to the question 5. It was found that six students who initially answered the question 5 correctly in the pre-test failed to answered it correctly in the post-test. This decrease in the correct percentage of the question 5 appeared to be largely associated with the students' careless mistakes when doing the calculations (see Figure 1).

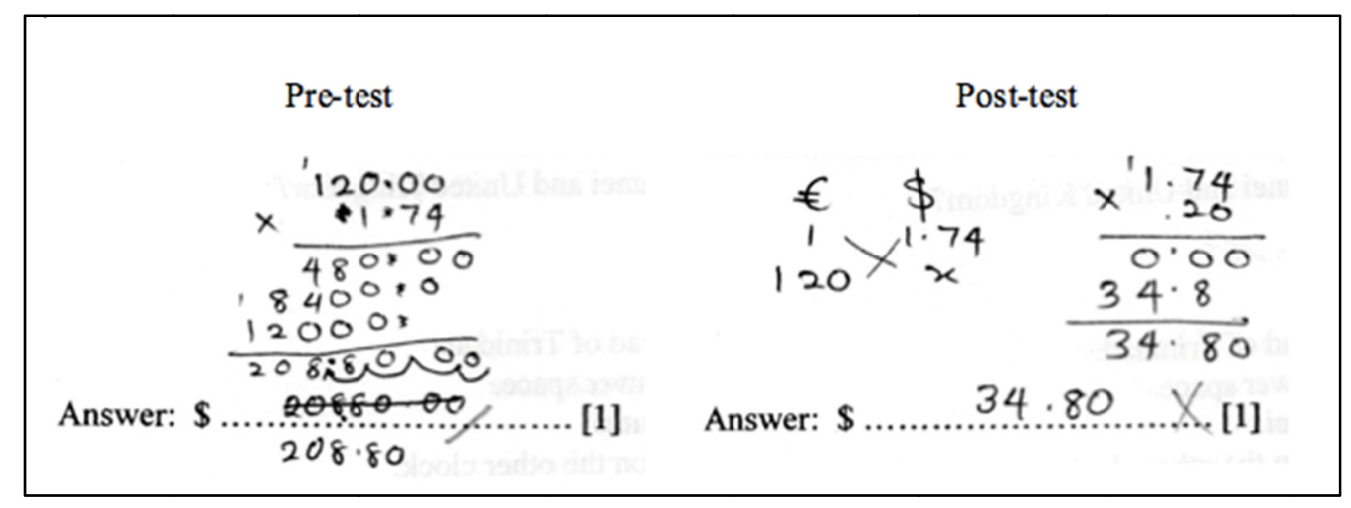

Figure 1. An example the students' careless mistakes in Question 5

As shown in Figure 1, the student successfully multiplied 120 by 1.74 in the pre-test. However, she made a careless mistake as she wrote 0.20 in the post-test. The other five students also made similar careless mistakes when multiplying and therefore, failed to answer the question correctly.

\section{Discussion}

As Lee and Bae (2007) noted, one of successful factors when implementing PBL is related to the efforts that the teacher made when playing a facilitator role in the classrooms. Consequently, it is important that as Ronis (2008) pointed out, teachers need to use different questioning skills/techniques to guide students towards the expected learning goals.

In this study, it was observed that the teacher made efforts to monitor the students' progress through different types of questioning techniques. For example, the teacher would ask questions to encourage students to review basic facts and skills that were required in the syllabus. She would also ask questions to further engage the students in critically thinking process by doubting the appropriateness of their solutions. It was also noticeable that the teacher's questioning helped initiate discussion among the group members (Shahrill \& Clarke, 
2014), which also motivated the students to collaboratively work as a group and learn from their peers and therefore, gradually reduced their dependence on the teacher during the course of the intervention (Adnan \& Shahrill, 2015; Caesar et al., 2016; Duraman et al., 2015; Han et al., 2016; Khalid \& Rahman, 2014; Lim et al., 2016; Othman et al., 2015). Indeed, it was observed that the students became more like independent learners with better presentation and communication skills after the intervention, in comparison with their performance at the first lesson when implementing PBL in their classroom.

It also appeared that the "Facts List" could be as a helpful tool to assist the teacher to keep track of the students' progress. The students noted down on the "Facts List" about what they already understood and what they had to do by using different resources in order to construct the solutions. Oftentimes, they mainly relied on searching the Internet to gather the information that they needed during the intervention. However, it is important to mention here that careful attention is needed to the use of the resource tools such as the Internet for future PBL implementation, although group browsing in the Internet appeared to be one of the collaboration tools for effective use in our study (Baden \& Wilkie, 2006). Partly because the information from the Internet was readily available at their fingertips, for example, the currency converter, the students might therefore not be aware and conscious that they needed to understand the concept of currency exchange.

\section{Conclusion}

The results from the students' performances on the pre-test and the post-test provided evidence to show that the implementation of PBL could have a positive impact on the students' development in the areas of the "real-life" and "syllabus-required" knowledge. As Burris and Garton (2007) pointed out, PBL can promote learners' acquisition of content knowledge and their knowledge of how to solve real-life problems.

The findings presented in this paper provide some insights into PBL implementation in a Year 9 mathematics classroom in Brunei Darussalam. Yet, further research is needed to follow up the issues that have been left unresolved due to the limitations of this study.

Firstly, only one class of 17 students and a teacher were involved in the study. We hope that the findings of our study can encourage more teachers to incorporate $\mathrm{PBL}$ in their practices. In this way, future mathematical PBL implementation and/or research could be conducted at school level, in order to understand how to better support teachers' professional development while implementing PBL.

Secondly, the design of a PBL problem is a challenging and time-consuming task for teachers. Therefore, it is important to call for more ongoing studies on how mathematics teachers can be helped to develop the necessary knowledge and skills that will enable them to create relevant PBL problems in mathematics.

Thirdly, the PBL intervention in this study was conducted in a short period time, mainly due to the busy school schedules and the time constraints. More empirical work is needed to further study how to deal with practical challenges and constraints in order for teachers to be better supported to adopt PBL in their practice. 


\section{References}

Adnan, N. H., \& Shahrill, M. (2015). Investigating the efficacy of problem-based learning intervention (PBLI) among lower secondary school students. Poster presented at the $7^{\text {th }}$ ICMI-East Asia Regional Conference on Mathematics Education (EARCOME 7), "In Pursuit of Quality Mathematics Education for All", Cebu City, Philippines, 11-15 May 2015. http://dx.doi.org/10.13140/RG.2.1.3548.5606

Baden, M., \& Wilkie, K. (2006). Problem-based learning online. Maidenhead: Open University Press.

Barrows, H. S., \& Tamblyn, R. S. (1980). Problem-based learning: An approach to medical education. New York: Springer.

Botty, H. M. R. H., \& Shahrill, M. (2014). The impact of Gagné, Vygotsky and Skinner theories in pedagogical practices of mathematics teachers in Brunei Darussalam. Review of European Studies, 6(4), 100-109. http://dx.doi.org/10.5539/res.v6n4p100.

Botty, H. M. R. H., \& Shahrill, M. (2015). Narrating a teacher's use of structured problem-based learning in a mathematics lesson. Asian Journal of Social Sciences \& Humanities, 4(1), 156-164.

Burns, R. B. (1997). Introduction to research methods. ( $3^{\text {rd }}$ ed.). Melbourne: Longman.

Burris, S., \& Garton, B. (2007). Effect of instructional strategy on critical thinking and content knowledge: Using problem-based learning in the secondary classroom. Journal of Agricultural Education, 48(1), 106-116.

Caesar, M. I. M., Jawawi, R., Matzin, R., Shahrill, M., Jaidin, J. H., \& Mundia, L. (2016). The benefits of adopting a problem-based learning approach on students' learning developments in secondary geography lessons. International Education Studies, 9(2), 51-65. http://dx.doi.org/10.5539/ies.v9n2p51

Chin, C., \& Chia, L. (2005). Problem-based learning: Using ill-structured problems in biology project work. Science Education, 90(1), 44-67.

Duraman, H. S. A. H., Shahrill, M., \& Morsidi, N. M. H. (2015). Investigating the effectiveness of collaborative learning in using the snowballing effect technique. Asian Journal of Social Sciences \& Humanities, 4(1), 148-155.

Ebert, E., \& Culyer, R. (2011). School: An Introduction to Education. Belmont, CA: Wadsworth.

Gillies, R., \& Boyle, M. (2010). Teachers' reflections on cooperative learning: Issues of implementation. Teaching and Teacher Education, 26, 933-940.

Han, S. H., Shahrill, M., Tan, A., Tengah, K. A., Jaidin, J. H., \& Jawawi, R. (2016). Administering problem-based learning ( $P B L$ ) approach in the teaching of college-level mathematics. Paper presented at the International Conference on New Horizons in Education, Vienna, Austria, July 13-15, 2016. http://dx.doi.org/10.13140/RG.2.1.3364.7608 


\section{Macrothink}

International Research in Education

ISSN 2327-5499

2016, Vol. 4, No. 2

Hung, W. (2011). Theory to reality: A few issues in implementing problem-based learning. Educational Technology Research and Development, 59, 529-552.

Jaidin, J. H. (2009). Conceptions of learning held by upper primary children in government schools in Brunei Darussalam (Unpublished doctoral thesis). Queenslland University of Technology, Brisbane, Australia.

Khalid, M., \& Rahman, H. (2014). Problem-based learning to enhance students' understanding and motivation for learning mechanical science. IIUM Journal of Educational Studies, 2(1), 56-66.

Lambros, A. (2002). Problem-Based Learning in K-8 Classrooms: A Teacher's Guide to Implementation. Thousand Oaks, CA: Corwin Press, Inc.

Lee, H., \& Bae, S. (2007). Issues in implementing a structured problem-based learning strategy in a volcano unit: A case study. International Journal of Science and Mathematics Education, 6, 655-676.

Leech, N. L., Barrett, K. C., \& Morgan, G. A. (2012). IBM SPSS for intermediate statistics: Use and interpretation. $\left(4^{\text {th }} \mathrm{ed}\right)$. New York: Routledge.

Li, H.-C. \& Stylianides, A. J. (2016). The roles of teacher and students during a problem-based learning intervention. Paper presented at the 13th International Congress on Mathematics (ICME-13), Hamburg, Germany, 24-31 July 2016.

Li, H.-C. (2011). The development of Taiwanese students' understanding of fractions: A problem-based learning approach. In, Proceedings of the British Society for Research into Learning Mathematics, 31(2), 25-30, Leeds, UK, 11 June 2011.

Li, H.-C. (2012). Implementing problem-based learning in a Taiwanese elementary classroom: a case study of challenges and strategies. Research in Mathematics Education, 14(1), 89-90.

Lim, M. T. L., Shahrill, M., Mundia, L., Tengah, K. A., Tan, A., \& Mahadi, M. A. (2016). An alternative approach to teaching: Implementing a cooperative learning strategy STAD at the junior college level. Advanced Science Letters, 22(5/6), 1725-1729. http://dx.doi.org/10.1166/as1.2016.6748

Ministry of Education. (2013). The National Education System for the 21st Century: SPN21 (Revised ed.). Bandar Seri Begawan, Brunei Darussalam: Ministry of Education.

Moore, A. (2012). Teaching and learning. ( $2^{\text {nd }}$ ed). London: Routledge.

Othman, H. R. H., Suhaimi, Z., Shahrill, M., \& Mahadi, M. A. (2015). To pair or not to pair: Investigating the dynamics of teacher-student interactions in different classroom settings. Turkish Online Journal of Educational Technology, September, 2015 Special Issue for INTE 2015, 675-684. http://dx.doi.org/10.13140/RG.2.1.4415.3046

Pallant, J. (2010). SPSS survival manual: a step by step guide to data analysis using SPSS for Windows (3rd ed.). Maidenhead: Open University Press. 
Pham, H. (2011). Theory-based instructional models applied in classroom contexts. Literacy information and Computer Education Journal, 2(2), 406-414.

Preechaporn, W., \& Tat, T. (2012). Problem-Based Learning the 4 Core Areas (PBL4C) Preparing Children for The Future. Paper presented at 15th UNESCO-APEID International Conference, Jakarta, Indonesia.

Punch, K. (2005). Introduction to Social Research: Quantitative and Qualitative Approaches. $\left(2^{\text {nd }}\right.$ ed). London: SAGE.

Rashid, R., \& Jaidin, J. H. (2014). Exploring primary school teachers' conceptions of 'formative assessment for learning'. International Education Studies, 7(9), 69-83.

Reeve, J. (2006). Teachers as facilitators: what autonomy-supportive teachers do and why their students benefit. The Elementary School Journal, 106, 225-236.

Ronis, D. (2008). Problem-Based Learning for Math and Science: Integrating Inquiry and the Internet. ( $2^{\text {nd }}$ ed.). Thousand Oaks, CA: Corwin Press.

Rudner, L. M., \& Schafer, W. D. (2002). What teachers need to know about assessment. Washington, DC: National Education Association.

Salam, N. H. A., \& Shahrill, M. (2014). Examining classroom interactions in secondary mathematics classrooms in Brunei Darussalam. Asian Social Science, 10(11), 92-103. http://dx.doi.org/10.5539/ass.v10n11p92

Shahrill, M. (2009). From the general to the particular: Connecting international classroom research to four classrooms in Brunei Darussalam (Unpublished doctoral dissertation). University of Melbourne, Melbourne, Australia.

Shahrill, M. (2013a). Review of teacher questioning in mathematics classrooms. International Journal of Humanities and Social Science, 3(17), 224-231.

Shahrill, M. (2013b). Comparing teacher questioning in American and Australian mathematics classrooms. Journal of Applied Research in Education, 17, $26-40$.

Shahrill, M., \& Clarke, D. J. (2014). Brunei Teachers' Perspectives on Questioning: Investigating the Opportunities to 'Talk' in Mathematics Lessons. Intermational Education Studies, 7(7), 1-18.

Shahrill, M., \& Mundia, L. (2014). The use of low-order and high order questioning in Mathematics Teaching: Video analyses case study. Journal of Studies in Education, 4(2), 15-34.

Stake, R. E. (1995). The art of case study research. Thousand Oaks, CA: Sage.

Vygotsky, L. S. (1978). Mind in society: the development of higher psychological processes. Cambridge, MA: Harvard University Press.

Wang, H., \& Posey, L. (2011). An inquiry-based linear algebra class. US-China Education Review, 489-494. 


\section{Macrothink}

International Research in Education

ISSN 2327-5499 2016, Vol. 4, No. 2

Watkins, C., Carnell, E., \& Lodge., C. (2007). Effective learning in classrooms. Thousand Oaks: Paul Chapman Publishing.

Wirkala, C., \& Kuhn, D. (2011). Problem-based learning in K-12 education: is it effective and how does it achieve its effects? American Educational Research Journal, 48(5), 1157-1186.

\section{Copyright Disclaimer}

Copyright reserved by the authors.

This article is an open-access article distributed under the terms and conditions of the Creative Commons Attribution license (http://creativecommons.org/licenses/by/3.0/). 